\title{
A Research on Supplier Selection Method for CALS
}

\author{
Xiaoying Xi and Lili Jiang \\ School of Mechanical and Electronic Engineering, Guangdong University of Technology, \\ Guangzhou 510006, P.R. China \\ yingxiaoxi@126.com jiang_11@21cn.com
}

\begin{abstract}
Based on the characteristics of supplier selection for CALS(Continuous Acquisition and Life-cycle Support), that companies with CALS have many suppliers and suppliers are always strategic suppliers, supplier selection process is divided into two phases: pre-selection and making decision. At supplier pre-selection stage, polychromatic sets theory from Russia is introduced as the solution scheme. According to the properties of suppliers themselves and pre-selection evaluating indicators, pre-selection contour Boolean matrix is created automatically. Based on it, supplier pre-selection model is set up. At decision-making stage, popular fuzzy analytic hierarchy process is adopted to set up supplier selection model. On the basis of evaluating indicators of the decision-making stage, the best supplier can be chosen quickly. In the end, an application example of motor company is given to testify the feasibility and effectiveness of the proposed method.
\end{abstract}

Keywords: CALS, Supplier selection, Pre-selection, Polychromatic sets, Fuzzy analytic hierarchy process

\section{INTRODUCTION}

Since CALS was proposed in 1985 by the American Department of Defense, its application has been common day by day, and it has become the strategy of the enterprise's full-scale information development. Now many countries and organizations, such as America, Japan, English, Singapore and Taiwan area, are studying and popularizing CALS actively. But in our country, CALS is only on theoretic discussion stage, and concrete research job just begins.

As an important step for CAIS purchasing, supplier selection is also one of important decision-making questions for enterprise. Supplier influences the product quality, delivery date and competition of enterprise. Especially when the enterprise places its main energy more and more on its core business, contracting non-core business with the supplier, supplier selection appears more importantly.

\section{CHARACTERS OF SUPPLIER SELECTION FOR CALS}

Selection of contractors, sub-contractors and suppliers can all be considered as supplier selection. Characters of supplier selection for CALS are as follows:

Please use the following format when citing this chapter:

Xi, X., Jiang, L., 2007, in IFIP International Federation for Information Processing, Volume 255, Research and Practical Issues of Enterprise Information Systems II Volume 2, eds. L. Xu, Tjoa A., Chaudhry S. (Boston: Springer), pp. $1473-$ 1480 . 
(1) Meeting product lifecycle support

Since CALS is defined as continuous acquisition and lifecycle support, supplier selection for CALS must meet the demand of product lifecycle support. That is to say product information from birth to death must be followed and queried, for example, we can inquire the part's supplier even at its maintenance stage. To achieve the purpose, the information between company and supplier, supplier and supplier must be integrated. Only in this way, information sharing is reached in deed and the demand of lifecycle support is met.

(2) Supplier is strategic cooperative comate

Companies in CALS generally purchase material and machine parts in other companies, suppliers are very important for this kind of company, and belong to strategic suppliers. So supplier selection method and assessment index must accord with strategic supplier selection.

(3) Supplier pre-selection occupies an important position

In order to cooperate with best supplier, company searches suppliers in the whole world; therefore, many suppliers can be chosen. If not pre-selecting but making decision directly on suppliers, decision-making will face many difficulties. Now, companies always pre-select suppliers artificially by some assessment indexes. But it is inefficient and inaccurate by this artificial way.

Up to now, research on supplier pre-selection is little. Literature [1] adopts fuzzy cluster analysis as pre-selection method, and uses analytic hierarchy process to count the weights of evaluating indicators. The defect of this method is complicated model and huge computational complexity, especially when there are many pre-selection evaluating indicators in company. Literature [2] pre-selects suppliers by fuzzy search method, namely uses information retrieval method to pre-select potential suppliers. This method maybe lead too many suppliers satisfied the conditions, thereby gives many jobs to decision-making stage. Literature [3] considers the main jobs of supplier pre-selection are the definition of need, review purchase requisition and setup of evaluating indicators which is subjective; therefore the pre-selection stage should be left to humans rather than machines. Although the definition of need, review purchase requisition and setup of evaluating indicators must be considered in pre-selection stage, if company has many suppliers, a good pre-selection method is also required. So in this paper, supplier selection process is divided into two phases: Pre-selection and making decision. At supplier pre-selection stage, polychromatic sets theory from Russia good at simulation on hierarchical structure is introduced as the solution scheme. At decision-making stage, popular fuzzy analytic hierarchy process is adopted to set up supplier selection model.

\section{SUPPLIER PRE-SELECTION BASED ON POLYCHROMATIC SETS CONTOUR BOOLEAN MATRIX}

\subsection{Advantages of Polychromatic Sets}

Polychromatic sets theory, which is a new system theory and tool on dealing with information, is put forward by Russian Professor V. V. Pavlov [4-5]. It uses the formally same mathematics model to emulate different objects, which makes 
emulating system more flexible. Moreover, it fits to solve the problems with hierarchical structure, and supplier selection is just this kind of problem. Added to this, polychromatic set has the advantage of algorithmic adaptability, even if supplier amount changes, supplier selection algorithm doesn't need to alter.

\subsection{Polychromatic Sets Contour Boolean Matrix}

For the conventional set $\mathrm{B}=\left(b_{1}, b_{2}, \ldots, b_{n}\right)$, an element $b_{i}(i=1,2, \ldots, n)$ is distinguished from other elements by its name only, and other properties of the element are not expressed in this expression. From literature [6-7], we can see in the theory of polychromatic sets, suppose $A=\left(a_{1}, a_{2}, \ldots, a_{n}\right)$ is an element set, an element $a_{i}(i=1,2, \ldots, n)$ in $A$ can be distinguished from other elements by not only its name but also other properties of the element. Suppose $F(A)=\left(F_{l}, F_{2}, \ldots, F_{m}\right)$ is the aggregation of properties. Contour Boolean matrix $[A \times F(A)]$ represents the relationship between an element $a_{i}$ and $F_{j}$. In this Boolean expression, if $a_{i}$ and $F_{j}$ is related, then $a_{i(j)}=1$, otherwise $a_{i(j)}=0$, and $F_{j}(\mathrm{~A})=\left(a_{i(j)}, a_{2(j)}, \ldots, a_{n(j)}\right)$. The establishment of this contour Boolean matrix is according to the information or experience of real world. As for supplier pre-selection, contour Boolean matrix is set up based on pre-selection indexes and suppliers' own properties.

$$
\left\|C_{i(j)}\right\|_{A, F(A)}=[A \times F(A)]=\left[\begin{array}{ccccc}
F_{1} & \ldots & F_{j} & \ldots & F_{m} \\
a_{1(1)} & \ldots & a_{1(j)} & \ldots & a_{1(m)} \\
\cdots & \ldots & \cdots & \cdots & \cdots \\
a_{i(1)} & \cdots & a_{i(j)} & \cdots & a_{i(m)} \\
\cdots & \ldots & \cdots & \cdots & \cdots \\
a_{n(1)} & \cdots & a_{n(j)} & \cdots & a_{n(m)}
\end{array}\right] \begin{gathered}
a_{1} \\
\cdots \\
a_{i} \\
a_{n}
\end{gathered}
$$

\subsection{Pre-selection Model based on Contour Matrix}

As for supplier pre-selection, most companies establish the pre-selection indexes according to their actual situations. We can pre-select suppliers in accordance with pre-selection indexes and suppliers' own properties. The variables and steps of this model are as follows:

(1) Variables of Pre-selection

We suppose $\left\{a_{1}, a_{2}, \ldots, a_{m}\right\}$ is the aggregation of suppliers; $\left\{O_{1}, O_{2}, \ldots, O_{n}\right\}$ is the pre-selection indexes sort and $O_{i j}$ is No. $j$ property of pre-selection index $O_{i}$ $\left(i=1,2, \ldots n, j=1,2, \ldots m_{i}\right) ;\left\{S_{i}\right\}$ represents the aggregation of pre-selection indexes chosen and $S_{i} \in\left\{O_{i l}, O_{i 2}, \ldots . O_{i} m_{i}\right\}(i=1,2, \ldots, n)$.

(2) Steps of Pre-selection 
1) The aggregation of suppliers is regarded as $A$, and Aggregation of pre-selection indexes $\left\{O_{i j}\right\}$ as $F(A)$.

2) Based on suppliers information and formula (1), setting up contour matrix $[A X$ $F(A)\}$ between suppliers $\left\{a_{1}, a_{2}, \ldots, a_{m}\right\}$ and pre-selection indexes $\left\{O_{i j}\right\}$.

3) Suppose i equals 1 , according to contour matrix $[A \times F(A)]$, we can obtain the value aggregation of $F_{s_{1}}(A)$.

4) Repeating step 3) until $\mathrm{i}=\mathrm{n}$. Then $F_{s_{1}}(A), \quad F_{s_{2}}(A) \ldots \ldots F s_{n}(A)$ is obtained.

5) Using $F_{P}(A)$ to express the result of $F s_{1}(A) \cap F s_{2}(A) \cap \ldots \cap F s_{n}(A)$.

6) If the element $F_{P}\left(a_{i}\right)$ in $F_{P}(A)$ equals 1 , supplier $a_{i}$ is the supplier meets the requirements.

7) End.

\section{SUPPLIER DECISION-MAKING BASED ON FUZZY ANALYTIC HIERARCHY PROCESS}

At decision-making stage, analytic hierarchy process is often adopted as evaluating method. But it has some defects, such as difficulty in consistency checkout. So we take fuzzy analytic hierarchy process as supplier decision-making method.

Using this method, there are six steps:

Step 1 Setting up hierarchical structure

We can create evaluating index hierarchical structure by topmost level, some medium levels and lowest level.

Step 2 Constructing fuzzy judgment matrix

Fuzzy judgment matrix $F$ expresses the comparison of importance on elements in the same level relative to an element of next higher layer. According to importance metric value comparing $a_{i}$ to $a_{j}$, fuzzy judgment matrix as follows can be obtained:

$$
\mathbf{F}=\left(\begin{array}{ccccc}
a_{I I} & a_{12} & \ldots \ldots \ldots \ldots & a_{I n} \\
a_{21} & a_{22} & \ldots \ldots \ldots \ldots \ldots & a_{2 n} \\
\ldots \ldots & \ldots \ldots & \ldots \ldots & \ldots \ldots \ldots \\
a_{n 1} & a_{n 2} & \ldots \ldots \ldots \ldots & a_{m n}
\end{array}\right)
$$

Properties of matrix $F$ are: (1) $0<a_{i j}<1$, and the value must be $0.1,0.2, \ldots, 0.9$; (2) $a_{i i}=0.5, \mathrm{i}=1,2, \ldots, \mathrm{n} ;(3) a_{i j}=l-a_{j i}, \mathrm{i}, \mathrm{j}=1,2, \ldots, \mathrm{n}$.

Step 3 Checkouting the consistency

Consistency standard is D-value of corresponding elements of rows is constant.

Step 4 Calculating monolayer weight

Monolayer weight is the importance order of elements relative to the element of next higher layer. From literature [8], calculating formula of monolayer weight $\alpha_{i}$ is as formula (3): 


$$
\alpha_{i}=\frac{1}{n}-\frac{1}{n-1}+\frac{2}{n(n-1)} \sum_{k=1}^{n} a_{i k}
$$

Step 5 Calculating composing weight

The weight of the element of lowest level relative to topmost level is the composing weight. Recurrence method uses commonly. Suppose there are $\mathrm{n}_{k}$ elements on kth level, and the weight vector aggregation in relation to topmost level is $W_{W_{k}{ }^{3}}$. Based on recursion rule, the composing weight of the element on lowest level is as formula (4):

$$
W_{n}^{1}=W_{n}^{n-1} \cdot W_{n-1}^{n-2} \cdots \cdot W_{3}^{2} \cdot W_{2}^{1}=\prod_{i=2}^{n} W_{i}^{i-1}
$$

Step 6 Assessing and computing the score of suppliers

Generally speaking, assessing person marks the indexes of lowest level. If score aggregation of sub indexes is $\mathrm{X}=\left(x_{l}, x_{2}, \ldots, x_{n}\right)^{T}$, and their composing weight aggregation is $\mathrm{W}=\left(w_{1}, w_{2}, \ldots, w_{n}\right)$, the formula of supplier's score is as formula (5). Supplier who gets the topmost score is the best supplier.

$$
S=W^{T} X=\sum_{i=1}^{n} w_{i} x_{i}
$$

\section{EXAMPLES}

Now, we take a motor company as our example. It has many suppliers, and supplier pre-selection and decision-making system has set up.

Step 1 Supplier pre-selection

Suppose pre-selection indexes of the company are as follows:

(1) Ownership: state enterprise (We consider it as $F_{l}$ ) and private enterprise (namely $F_{2}$ )

(2) Company Address: Guangdong province (namely $F_{3}$ ) and other area (namely $\left.F_{4}\right)$

(3) Total Assets: below 5 millions (namely $F_{5}$ ) and above 5 millions (namely $F_{6}$ )

Suppose the company has four suppliers, and the properties of suppliers are as follows:

Supplier A (We consider it as $a_{l}$ of A): state enterprise; Guangdong Province; 3.8 million;

Supplier B (namely $a_{2}$ ): state enterprise; Guangdong Province; 8 million;

Supplier C (namely $a_{3}$ ): private enterprise; Shandong Province; 1 million;

Supplier D (namely $a_{4}$ ): state enterprise; Guangdong Province; 4.5 million;

Now, the pre-selection indexes chosen are: State enterprise, Guangdong province, Total assets below 5 million.

According to step 1) 2) of pre-selection, contour Boolean matrix as Table 1. can be obtained: 
Table 1. A Contour Matrix

\begin{tabular}{|c|c|c|c|c|c|c|}
\hline $\begin{array}{c}\text { Properties } \\
\text { Supplier }\end{array}$ & $F_{1}$ & $F_{2}$ & $F_{3}$ & $F_{4}$ & $F_{5}$ & $F_{6}$ \\
\hline$a_{I}$ & 1 & 0 & 1 & 0 & 1 & 0 \\
\hline$a_{2}$ & 1 & 0 & 1 & 0 & 0 & 1 \\
\hline$a_{3}$ & 0 & 1 & 0 & 1 & 1 & 0 \\
\hline$a_{4}$ & 1 & 0 & 1 & 0 & 1 & 0 \\
\hline
\end{tabular}

Now, the pre-selection indexes chosen are State enterprise, Guangdong province and Total assets below 5 million, namely $\left\{S_{i}\right\}=\left(F_{l}, F_{3}, F_{5}\right)$. From above contour Boolean matrix, we can see $F_{1}(A)=(1,1,0,1), F_{3}(A)=(1,1,0,1), F_{5}(A)=(1,0,1,1)$, then $F_{P}(A)=\mathrm{F}_{1}(\mathrm{~A}) \cap \mathrm{F}_{3}(\mathrm{~A}) \cap \mathrm{F}_{5}(\mathrm{~A})=(1,0,0,1)$. Because $F_{P}\left(a_{1}\right)=1$ and $F_{P}\left(a_{4}\right)=1$, supplier A and Supplier $D$ is the suppliers meet pre-selection indexes chosen.

Step 2 Choose the best supplier based on fuzzy analytic hierarchy process

In step 1, we have pre-selected supplier A and Supplier D. Suppose evaluating indexes and the hierarchical structure of the motor company are as Figure 1:

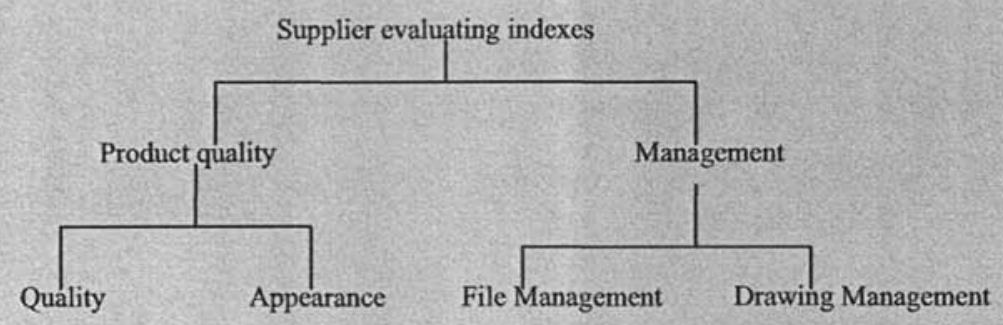

Figure 1. Supplier Evaluating Indexes

According to index importance degree and formula (3), monolayer weight of all indexes can be obtained. Suppose it is as Figure 2. Using formula (4), we can get composing weight of indexes on lowest level as Table 2. From Table 2, we can see composing weight of quality is $0.42(0.6 \times 0.7)$, composing weight of appearance is 0.28 , composing weight of file management is 0.15 , composing weight of drawing management is 0.15 . 


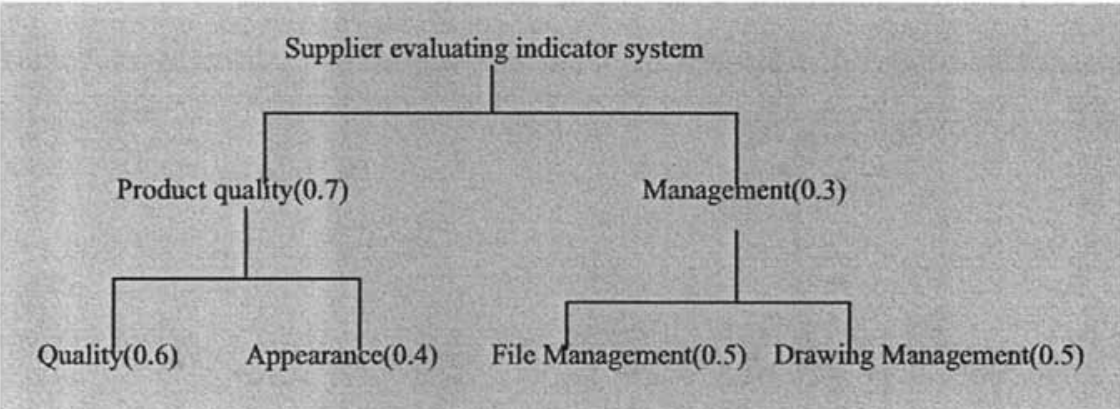

Figure 2. Monolayer Weight of all Indexes

Table 2. Composing Weight of Indexes on Lowest Level

\begin{tabular}{|c|c|c|c|c|}
\hline & Quality & Appearance & File Management & Drawing Management \\
\hline $\begin{array}{c}\text { composing } \\
\text { weight }\end{array}$ & 0.42 & 0.28 & 0.15 & 0.15 \\
\hline
\end{tabular}

Managers of the company mark the indexes of lowest level according to suppliers' behavior. Now we suppose that the lowest level indexes score are as Table 3 .

Table 3. The Score of Lowest Level Indexes of Supplier A and D

\begin{tabular}{|l|c|c|c|c|}
\hline & Quality & Appearance & File Management & Drawing Management \\
\hline Supplier A & 90 & 80 & 88 & 86 \\
\hline Supplier D & 85 & 90 & 89 & 90 \\
\hline
\end{tabular}

Based on composing weight of Table 2 and the score of Table 3, using formula (5), the score of supplier A and D can be obtained. The total score of supplier A is 86.3 $(90 \times 0.42+80 \times 0.28+88 \times 0.15+86 \times 0.15)$ and the total score of supplier D is 87.75 $(85 \times 0.42+90 \times 0.28+89 \times 0.15+90 \times 0.15)$, so supplier $\mathrm{D}$ is the best supplier.

\section{CONCLUSIONS}

In this paper, we bring forward supplier selection method for CALS, and use polychromatic sets contour Boolean matrix into supplier pre-selection, then use fuzzy analytic hierarchy process at decision-making stage. Using this method can choose suppliers accurately and quickly, thus bring great economic benefit for enterprise. 


\section{REFERENCES}

1. C. Jin, Z. Ji, and Y. Lin, Strategy on Supplier Selection of Shipbuilding Enterprises, CIMS. Volume 9, Number 10, pp.886-890, (2003).

2. X. Li, C. Wu, and L. Liu, Research on Vendor Selection in Vertical Business-to-Business Marketplace, CIMS. Volume 9, Number 4, pp.270-275, (2003).

3. R. Davidrajuh, Automating Supplier Selection Procedures. Ph. D Thesis, Norwegian University of Science and Technology (2001).

4. V.V. Pavlov, Polychromatic sets in the systems theory: changes in the composition of $\pi \mathrm{S}-$ sets, Informatsionnye Tekhnologii. Number 1, pp.4-8, (1998).

5. Z. Li, Polychromatic Sets and its Application in Simulation of Complex Object and System, Information and Control. Volume 30, Number 3, pp.204-208, (2001).

6. L. Jiang, X. Xi, M. Li, and $\mathrm{Z}$. Li, Research on conceptual design of jig and fixture based on polychromatic sets, China Mechanical Engineering. Volume 17, Number 8, pp.832836, (2006).

7. S. Li, Z. Li, and F. Tang, Conceptual design of machining center by using polychromatic sets theory, Chinese Journal of Mechanical Engineering. Volume 40, Number 6, pp.118$122,(2004)$.

8. J. Zhang, Fuzzy Analytic Hicrarchy Process, Fuzzy System and Mathematics. Volume 14, Number 2, pp.80-85, (2000). 